\title{
The Metaphysics of Mortals: Death, Immortality, and Personal Time
}

\author{
Cody Gilmore \\ UC Davis
}

\section{Introduction}

Lewis (1976) distinguishes between external time and personal time. 'External time' is a name for a certain thing - time itself. 'Personal time' is not a name for any one thing; each person has her own personal time. As Lewis puts it, 'the personal time of a particular time traveller. . . [is] roughly, that which is measured by his wristwatch' (1976: 146). An object's personal time, for Lewis, is what falls out of step with external time in cases in which that object travels in time.

Sorensen (2005) argues that, with respect to questions about the evil of death and the value of immortality, what matters are facts about how our lives are organized in personal time, not external time. Even if I continue to be alive in external time for infinitely many years, I ought to regard this as being as bad as imminent death if I'm allowed only one hour of personal time spread out across those years: 30 minutes of external time for the first 30 minutes of personal time, another 30 minutes of external time for the next 15 minutes of personal time, another 30 minutes of external time for the next $7 \frac{1}{2}$ minutes of personal time, and so on. ${ }^{1}$ Conversely, if I were going to cease to exist one hour from now in external time but I somehow managed to pack infinitely many years of personal time into that hour (one year of personal time in the first $1 / 2$ hour, the next year of personal time in the next $1 / 4$ hour, and so on), in such a way that there is no final year of my personal time, I ought to regard this as being almost as good as 'normal immortality'. ${ }^{2}$

Sorensen's claims fall within the domain of value theory. Personal time, as opposed to external time, has a certain kind of value or normative significance, according to Sorensen. But there are metaphysical issues nearby, and those will be my focus here. Personal time, I argue, should replace external time in some of our theorizing about the nature of death and immortality. Personal time has a certain role to play in the correct account of what death and immortality are. Saying what, precisely, that role is, and what role remains for external time, is not straightforward. In the end everything falls neatly into place, but these matters must be handled with care.

The plan is as follows. Sections $2-9$ formulate and defend an account of death. Section 10 does the same for immortality.

\section{Personal Time}

According to Lewis, the personal time of an object o of kind $\mathrm{K}$ is an entity $\mathrm{T}$ such that the regularities in o's career hold with respect to $T$ in the same way that the regularities in the career of a typical member of kind $\mathrm{K}$ hold with respect to time itself. So, if I undergo the amount of change (in terms of cell division, telomere shortening, digestion, hair growth, heartbeats, accumulation of new memories and loss of old ones, etc.) that a human being

\footnotetext{
${ }^{1}$ This case is adapted from Moore (1990: 228). See also Barrow (2005: 259). For a reply to Sorensen, see Nowacki (2006).

${ }^{2}$ Tipler (1994: 128-138) discusses similar cases and argues that they are physically possible. Richmond (2013) discusses possibilities for eternal damnation in temporally finite worlds in light of variations on these cases.
} 
would typically undergo in two hours, and if the stages of those processes are causally related to one another in the right way, then two hours of my personal time have elapsed for me, regardless of whether this occurs in one minute, or two hours, or four hours of external time. Indeed, the two hours of my personal time might be scattered across external time, so that the first hour is confined to 2015 and the second hour to 2050, in which case I have jumped forward in time.

Alternatively, the two hours of my personal time, along with the causal processes occurring within my body, might be oriented backward in external time, so that later events in my body cause earlier events in my body and my biological processes occur in reverse. An external observer would describe these processes by saying that my hair is getting gradually shorter, my blood is flowing backward, and so on. In such a case I travel backward in time. I might even discontinuously jump backward in time, disappearing at one time, $t_{2}$, and reappearing 500 years earlier, at $t_{1}$. If I have memories at $t_{1}$ of what happens to me at $t_{2}$, if my intrinsic properties at $t_{1}$ are typical of a person who was just in the overall intrinsic condition that I was in at $t_{2}$, and if I am the way I am at $t_{1}$ largely because I am the way I am at $t_{2}$, then the events in my life at $t_{1}$ count as being later with respect to my personal time than the events in my life at $t_{2}$, and I count as having travelled backward in time.

In the remainder of the paper, I discuss cases involving discrepancies between external time and the personal time of some living organism. Questions can be raised about the possibility of these cases. But this is not the place to address them. For a general defense of the metaphysical possibility of such cases, see Lewis (1976), and for more recent discussion, see Smith (2013) and Bernstein (2015). My goal is not to show that these cases are possible. It is to find out what we need to say about the nature of death and immortality if they are.

\section{Death and External Time}

What is it to die at a time? I defended an answer in Gilmore (2013). There I mentioned that my answer, like all extant answers, is vulnerable to time travel-based counterexamples, some like Sorensen's cases, others quite different. I suggested that a repair would probably need to invoke the notion of personal time, but I didn't say exactly how. ${ }^{3}$ In the next section I look systematically at a wider range of cases, and I develop an account of death that handles them.

I will start with a principle that I call the Cessation Thesis, which says that to die at a time is to cease to be alive at that time. To express this idea more precisely, I will need to introduce some machinery.

\subsection{Terminology and Technical Apparatus}

I assume that time is a continuum of instants, and that time as a whole may be either line-like (open) or circular (closed). ${ }^{4}$ I also invoke the notion of an interval. I assume that an

\footnotetext{
${ }^{3}$ And in my (2007b) I made the same points about my account of being dead at a time.

${ }^{4}$ Typically, 'time is a continuum of instants' is taken to mean that (i) time is the set that includes all and only the instants, (ii) the earlier than relation is a linear order (a transitive, asymmetric, and total relation) on this set, (iii) any partition of this set into two non-empty subsets s1 and s2 such that each instant in s1 is earlier than each instant in s2 (any cut of the set) must be such that either s1 has last instant and s2 has no first instant or s1 has no last instant but $\mathrm{s} 2$ has a first instant. For the set to count as a linear continuum, two further conditions must be
} 
interval is a non-empty set of instants that meets certain further conditions. ${ }^{5}$ Informally, if one thinks of instants as time points, then one should think of intervals as sets corresponding either to time points or to (non-scattered) time chunks, which may be of either finite or infinite duration, and which may or may not include any instants that bound them. The idea is that if a set $s$ is an interval, then for any two instants $t$ and $t^{*}$ in $s$, there must be way to draw a line from t to $t^{*}$, or vice versa, so that one never picks up one's pencil, one's pencil never leaves $s$, and one's pencil always moves in the direction of its local future.

Formal definitions of 'interval' and 'continuous' typically appeal to an asymmetric and transitive binary relation, e.g., being earlier than. But these definitions do not allow for the possibility that time is circular and still a continuum. ${ }^{6} \mathrm{~A}$ more neutral system of definitions would draw from the mathematical theory of cyclic orders and invoke a ternary relation expressed by 'after $a, b$ comes before $c$ ' - that has analogues of the properties of asymmetry and transitivity. ${ }^{7}$ To state the definition of 'continuous' in a way that presupposes neither that time is open nor that it is closed is a complicated affair, however, and would not repay the effort here. For a sketch of the some of the groundwork and a definition of 'interval', see note $8 .^{8}$

met, which I omit here. A binary relation $\mathrm{R}$ is transitive iff for any $\mathrm{x}, \mathrm{y}, \mathrm{z}$, if Rxy and Ryz then Rxz; asymmetric iff for any $x$ and $y$, if Rxy then not Ryx; and total iff for any $x, y$, either Rxy or Ryx or $x=y$.

${ }^{5}$ Standardly, the further condition is that the set must include any instant that is between any instants that it includes, where ' $t$ is between $t^{*}$ and $t^{* * \prime}$ means 'either $t^{*}$ is earlier than $t$ and $t$ is earlier than $t^{* *}$ or $t^{* *}$ is earlier than $t$ and $t$ is earlier than $t^{* \prime}$. But if time is circular, then every instant is earlier than every instant, including itself, and so for any instants $t, t^{*}$, and $t^{* *}, t$ is between $t^{*}$ and $t^{* *}$. And in that case the only way for a set to meet the 'further condition' is for it to include every instant! So a better definition of 'interval' would be framed in terms of the ternary relation mentioned in the main text below.

${ }^{6}$ If time is circular, then each instant is earlier than itself, in which case earlier than is not asymmetric on the set of instants, and as a result time does not count as a continuum, according to the standard definition.

${ }^{7}$ For further discussion of the difficulties of characterizing the structure of circular time in terms of a binary relation, see van Fraassen (1970: 66-70) and Newton-Smith (1980: 57-78). Oddly, when discussing alternative characterizations that invoke temporal relations of adicity greater than two, neither van Fraassen nor NewtonSmith mentions the ternary relation 'after $a, b$ comes before $c$ '. Instead, both jump to the four-place relation of pair separation. Unlike 'after $a, b$ comes before $c$ ', pair separation makes no distinction of orientation - e.g., between the points on a circle ordered by clockwise arrows and those same points, in the same positions, ordered by counterclockwise arrows.

${ }^{8}$ The analogues of transitivity and asymmetry are:

Transitivity* if $R(a, b, c)$ and $R(a, c, d)$ then $R(a, b, d)$ if $R(a, b, c)$ and $R(b, d, c)$ then $R(a, d, c)$

if $R(a, b, c)$ and $R(d, b, a)$ then $R(d, b, c)$

Asymmetry* if $R(a, b, c)$ then: not $R(c, b, a)$ and not $R(a, c, b)$ and not $R(b, a, c)$

The second and third clauses of Transitivity* and second two conjuncts of the consequent of Asymmetry* are redundant given a cyclicity principle (if $R(a, b, c)$ then $R(b, c, a)$ ) and hence are almost always omitted. Since I do not presuppose cyclicity, I retain them. From Asymmetry* it follows that if $R(a, b, c)$ then $a, b$, and $c$ are pairwise non-identical, hence that $R$ is irreflexive in the relevant sense. The view that time is dense can be stated as

Density* if $R(a, b, c)$ then: $\exists x R(a, x, b)$ and $\exists x R(b, x, c)$.

Finally, an interval can be defined as a set $s$ of instants such that: (1) $s$ has either exactly one or at least three members, (2) $R$ is total* over s, i.e., for any members $a$, $b$, and $c$ of $s:$

Totality* if $[a \neq b \& b \neq c \& a \neq c]$ then either: $[R(a, b, c)$ or $R(a, c, b)$ or $R(b, a, c)$ or $R(b, c, a)$ or

$R(c, a, b$,$) or R(c, b, a)]$,

and (3) for any members $a, b$, and $c$ of $s$ such that $R(a, b, c)$ : (i) if $R(c, a, b)$ then either 
In what follows, I will make frequent use of the notions of a starting point and an endpoint and, more generally, a boundary point, of an interval, and I will understand these notions in the typical way, modulo the technical apparatus needed to retain neutrality with regard to circular time. I will confine my formal definitions to notes, ${ }^{9}$ but I want to spend some time discussing examples.

So far as our definitions go, there could be intervals that have no boundary points. For example, if time is analogous to the real line or to a circle, then it's an interval with no boundary points. Some intervals could have a starting point but no endpoint and others, vice versa. If time is analogous to the non-negative reals, then time as a whole is an interval with a starting point (the 'zero instant') but no endpoint. Alternatively, suppose that time is analogous to the entire real line, and let $s$ be a set whose members are just some instant $t$ and all later instants. Then $\mathrm{s}$ is an interval that includes its starting point, $\mathrm{t}$, and it has no endpoint. A related interval is the set $s^{-}$, which includes all and only those instants later than $t$. It excludes its starting point, $t$, and also has no endpoint. We can denote $s$ as $[t,+\infty)$ and $s-$ as $(t,+\infty)$.

To take a more exotic example that will be relevant later, suppose that time is analogous to an oriented circle, ordered by clockwise arrows, together with exactly one 'onramp', which is infinite in length. Now let $t^{*}$ be an instant in the on-ramp, and let $\mathrm{s}^{*}$ be the set that includes $t^{*}$ together with all later instants: all the instants that come later on the on ramp, together with all of the instants on the circle. This interval has a starting point, $t^{*}$, but it has no endpoint. Analogous examples can be given of intervals that have endpoints but no starting points.

Of course, many intervals have a starting point and an endpoint. If time is analogous to the real line, then for any two instants, $t_{1}$ and $t_{2}$, such that $t_{1}$ is earlier than $t_{2}$, there will be four intervals that all have $t_{1}$ as their starting point and $t_{2}$ as their endpoint: $\left(t_{1}, t_{2}\right)$, which excludes its boundary points, $\left[t_{1}, t_{2}\right]$, which includes them, and the half-open intervals $\left(t_{1}, t_{2}\right]$ and $\left[t_{1}, t_{2}\right)$, which include one and exclude the other.

Finally, it will be convenient to work with some special purpose terminology. I will say that $x$ 's lifespan is the set of instants at which $x$ is alive. I do not assume that a thing's lifespan

- for any $x$, if $R(a, x, c)$ then $x$ is in $s$, or

- for any $x$, if $R(c, x, a)$ then $x$ is in $s$,

and (ii) if not $R(c, a, b)$ then for any $x$, if $R(a, x, c)$ then $x$ is in $x$. The definition of 'continuous' is straightforward against the background of a cyclicity assumption or a non-cyclicity assumption, but it becomes much trickier without either assumption, so I will not attempt it here. For more details on cyclic orders, see Huntington (1924), Novak (1984) and the Wikipedia entry on 'Cyclic Order': https://en.wikipedia.org/wiki/Cyclic order.

${ }^{9}$ To say that $t$ is a starting point of $s$ is to say: (i) $s$ is an interval, (ii) for any member $y$ of $s$, if $y$ is not identical to $t$, then for some member $x$ of $s, R(t, x, y)$, (iii) for any $x$ and for any member $y$ of $s$, if $R(t, x, y)$, then $x$ is a member of $s$, and (iv) if $t$ is a member of $s$, then for any member $x$ of $s$ and for any $y$, if $R(x, y, t)$, then there is some $z$ such that $z$ is not a member of $s$ and $R(x, z, t)$. Clause (ii) ensures that all other members of the interval can be reached by 'moving forward' from t. Clause (iii) ensures that there is no gap between $t$ and s. Clause (iv) blocks the result that if $\mathrm{s}$ is like a circle ordered clockwise, then each instant in s counts as a starting point of s. The definition of 'endpoint' contains clauses with parallel functions. To say that $t$ is an endpoint of $s$ is to say: (i) $s$ is an interval, (ii) for any member $x$ of $s$, if $x$ is not identical to $t$, then there is some member $y$ of s such that $R(x, y, t)$, (iii) for any $y$ and any member $x$ of $s$, if $R(x, y, t)$ then $y$ is a member of $s$, and (iv) if $t$ is a member of $s$, then for any $x$ and any member $y$ of $s$, if $R(t, x, y)$, then there is some $w$ such that $w$ is not a member of $s$ and $R(t, w, y)$. Finally, to say that $t$ is a boundary point of $s$ is to say that $t$ is either a starting point or an endpoint of $s$. 
must always be an interval (hence non-scattered). Perhaps there could be a thing that has a scattered lifespan. ${ }^{10}$ However, I will often want to speak of maximal non- scattered periods of time within a thing's lifespan, so it will be useful to have a term for that as well. I will say that $y$ is a life-period of $x$ if and only if: (i) $y$ is an interval, (ii) $x$ is alive throughout (at each instant in) $y$, and (iii) $y$ is not a subset of any other interval throughout which $x$ is alive. So far as these definitions go, lifespans can be scattered, but life-periods cannot.

\subsection{The Cessation Thesis}

With all of the above in hand, the Cessation Thesis can be stated as:

C1 Necessarily, for any $x$ and any $y, x$ dies at $y$ if and only if $y$ is an endpoint of some life-period of $x$.

Three features of $\mathrm{C} 1$ are worth mentioning right away. First, it is neutral with regard to whether things continue to exist - as corpses or dead bodies, say - after they die. When a thing makes the transition from being alive to being dead, it is alive for a while, then not - regardless of whether the thing continues to exist. Second, C1 is neutral with regard to whether a thing is alive at the instant at which it dies. Suppose that Julia's lifespan is the interval $\left[t_{1}, t_{2}\right]$, so that Julia has a last instant of being alive but no first instant of no longer being alive. Then, despite the fact that Julia is alive at $t_{2}, C 1$ says that she dies at $t_{2}$. Now suppose that George's lifespan is the interval $\left(t_{1}, t_{2}\right)$, so that George has a first instant of no longer being alive but no last instant of being alive. In this case, he dies at an instant, $t_{2}$, at which he is not alive. (An endpoint of a given life-period may be but need not be included in that life-period.) Third, C1 is neutral with regard to whether a thing can be alive again after it dies. Suppose that Francis is alive throughout the 40 -year-long interval $\left[t_{0}, t_{1}\right]$, then dead but still existent (as a corpse) at each instant in the subsequent 1-hour-long interval $\left(t_{1}, t_{2}\right)$, then alive throughout the next 50year-long interval $\left[t_{2}, t_{3}\right)$, and not alive or existent at any instant thereafter. Then, according to $\mathrm{C} 1$, Francis dies at $t_{1}$, comes back to life at $t_{2}$, and dies for a second and final time at $t_{3}$. I regard all three of the features of $\mathrm{C} 1$ just noted as virtues, so I will be careful to preserve them in all subsequent accounts.

It should also be noted that C1 faces a pair of objections, pressed by Feldman (1992). First, Feldman argues that when an amoeba (e.g.) divides into two new amoebas, it ceases to exist, hence it ceases to be alive, but it doesn't die. Second, he argues that $\mathrm{C} 1$ is vulnerable to counterexamples involving suspended animation (also called cryptobiosis), a kind of reversible stasis, brought on by freezing or dehydration, in which an organism's metabolism and other life

\footnotetext{
${ }^{10}$ One might accept this possibility for at least three reasons. First, one might think that things are not alive when they are in a state of cryptobiosis (Gilmore 2013). (Whether or not they are dead while in cryptobiosis is a separate question.) Suppose that a tardigrade, $o$, is alive from $t_{1}$ to $t_{2}$, in cryptobiosis from $t_{2}$ to $t_{3}$, and alive again from $t_{3}$ to $t_{4}$, at which time it dies and never exists thereafter. Then, if $o$ is not alive when it is in cryptobiosis, its lifespan excludes $\left(t_{2}, t_{3}\right)$ and hence is gappy. Second, one might think that it is possible for there to be a thing that lives from $t_{1}$ to $t_{2}$, dies at $t_{2}$, is dead from $t_{2}$ to $t_{3}$, returns to life at $t_{3}$, then dies at $t_{4}$ and never exists thereafter. Again, the lifespan of such a thing would exclude $\left(t_{2}, t_{3}\right)$ and would be gappy. Third, a living thing might jump forward or backward in time in such a way that the thing is alive at any time at which it exists, though there are gaps in the set of instants at which it exists. Cases 2 and 3 in the main text below are of this kind.
} 
functions cease. He claims that when an organism enters suspended animation, it ceases to be alive but doesn't die. These problems for C1 are orthogonal to each other and to the problems I will raise in this paper. So, to avoid any unnecessary complexity, I will mostly ignore them. Eventually I will amend $\mathrm{C} 1$ to solve the problems about time travel that are the focus of this paper. Once these amendments have been formulated, they can be applied in a straightforward way to more complicated accounts of death (e.g., Gilmore (2013)) designed to handle fission and suspended animation.

4. Counterexamples to the Cessation Thesis

In this section I present four counterexamples to $\mathrm{C} 1$.

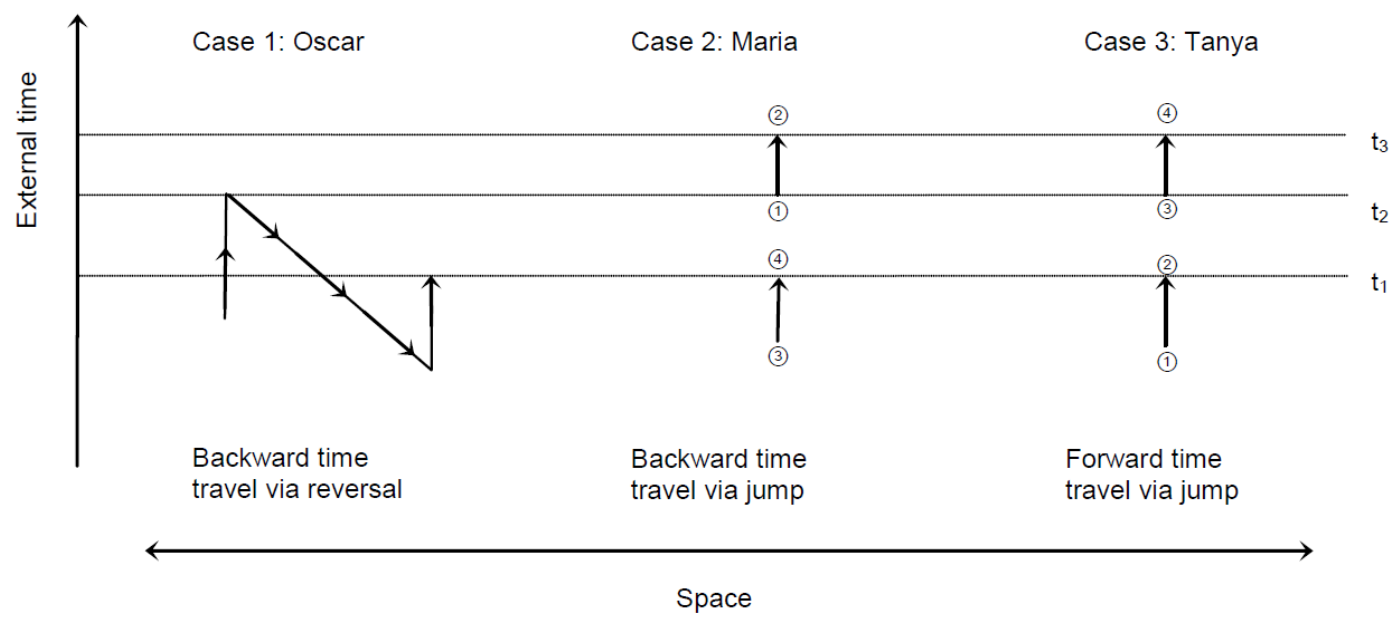

In the diagram, the direction of the time traveler's personal time and the direction of the causal processes occurring within her body are represented by the short arrows and/or the numbered circles. In each case, the personal time of the time traveler leads up to a sudden, violent event in which the person's body is destroyed in an explosion. Now let me explain why these cases are counterexamples to $\mathrm{C} 1$.

As applied to case 1, C1 yields two incorrect verdicts. First, it tells us that Oscar dies at $t_{2}$. For there is an interval ending at $t_{2}$ throughout which Oscar is alive (the interval $\left[t_{1}, t_{2}\right]$, for example), and Oscar is not alive at any instant after $t_{2}$. But in fact Oscar merely reverses his direction in time at $t_{2}$; he does not die at that time. If, from an early age, Oscar knows what will happen to him at $t 2$, the appropriate attitude for him to take to that instant is excitement, not dread. As the instant approaches, he is still in a position to anticipate more than half of his life!

Second, $\mathrm{C} 1$ tells us that Oscar does not die at $t_{1}$. For Oscar is alive at $t_{1}$ and throughout an interval that begins at $t_{1}$ : given what happens to Oscar in that part of his career represented by the 'left leg' of the ' $N$ '-shaped worldline, we know that he is alive from $t_{1}$ to $t_{2}$. But in fact Oscar dies at $t_{1}$ nonetheless. Having traveled to times before he was born, Oscar begins once again to persist through time in the normal way. In the final few minutes leading up to $t_{1}$, he sits 
at a café. Then a nearby meteorite impact vaporizes him. To sum up, C1 says that Oscar dies at $t_{2}$ and not at $t_{1}$. But in fact it's the other way around.

As applied to case 2, C1 counts Maria as dying at $\mathrm{t} 3$, since there is an interval leading up to $t_{3}$ throughout which she is alive, $\left[t_{2}, t_{3}\right]$, and since she is not alive at any later times. But in fact Maria doesn't die at $t_{3}$; she merely jumps backward in time then. In the minutes leading up to $t_{3}$, she is in a position to anticipate many years of her life. C1 also yields the verdict that Maria dies at $t_{1}$, which is correct. In the final minutes leading up to $t_{1}$, she sits with Oscar in the café. She too is vaporized.

Finally, as applied to case 3, C1 yields the verdict that Tanya dies at $t_{1}$, which is incorrect. In fact she merely jumps forward in time, rather than dying, at that instant. ${ }^{11} \mathrm{C} 1$ also yields the verdict that she dies at $t_{3}$, which is correct.

A fourth counterexample to C1 involves a 'rolled up' spacetime, in which the temporal dimension is circular. (To keep things simple I will assume that this spacetime is not relativistic.) In such a spacetime, one could revisit times through which one has already lived, and even interact with one's younger self, just by living long enough, so that the duration of one's life, as measured by one's personal time, is greater than the duration of external time as a whole, thought of as the temporal length of the circumference of the circle. ${ }^{12}$

Case 4: David

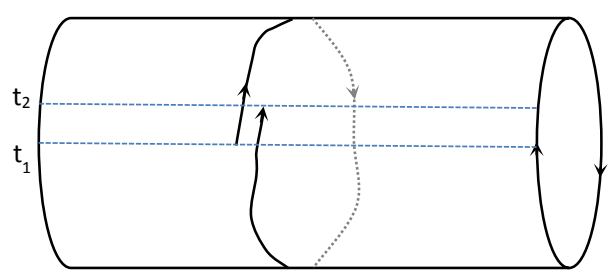

In case 4 , David is such a person. He is born at $t_{1}$ and, while still a child, is occasionally visited by an aged male relative. One day, this relative is sailing across the ocean, solo, when, at $t_{2}$, his vessel is struck by a meteorite and he is vaporized. David is saddened by the news, but he carries on and lives a happy life. He lives so long that he manages, as an old man, to get to know

\footnotetext{
${ }^{11}$ What is the difference between the case of Francis, who is described earlier as dying, then returning to life, and then dying again, and the case of Tanya? Informally, the difference is that there are stages of Francis's career that are 'causally between' the event that is her ceasing to be alive at $t_{1}$ and the event that is her becoming alive again at $t_{2}$, whereas there are no stages of Tanya's career that are 'casually between' the event that is her disappearance (and ceasing to be alive) at $t_{1}$ and the event that is her reappearance (and becoming alive again) at $t_{2}$. This causal difference gives rise to a difference in their respective personal times. Where ' $A$ ' represents a moment of personal time at which the associated entity is alive and ' $N$ ' represents a moment of personal time at which the associated entity is not alive, Francis's personal time is (considerations of density and continuity aside) like this: AAANNNAAA, whereas Tanya's personal time is like this: AAAAAA. (Tanya jumps from $t_{1}$ to $t_{2}$ after her third ' $A$ '.) Francis dies after her third ' $A$ ' and again after her sixth ' $A$ '. Tanya dies only after her sixth ' $A$ '. For a slight variation of the question, see section 9.

${ }^{12}$ Sorabji (2006: 321-322) discusses a case like this, though not in the context of any specific account of what it is to die. For a discussion of circular time and personal identity in the context of theories of eternal recurrence, see Jenkins (2012) and Bergström (2013).
} 
himself as a little boy. As he had suspected for decades, the man whom he remembers as his aged relative is himself. Embracing his destiny, he embarks upon his solo sailing journey and, some days later, just as he's about to turn 95, he is struck and vaporized by the meteorite.

As applied to case 4, C1 yields the verdict that David never dies, since, in that case, David is alive at every instant, and no instant is the endpoint of any of life-period of his. But in fact he does die, specifically at $t_{2}$.

\section{Death and Personal Time}

The necessary repair to $\mathrm{C} 1$ should already be pretty obvious, at least in rough outline. Here is a first approximation: to die is not to cease to be alive with respect to external time; it is to cease to be alive with respect to personal time.

\subsection{Terminology and Technical Apparatus}

To formulate this idea more precisely, I will need to make some assumptions about personal time, parallel to those I have been making about external time. I will assume that each material object (persons included) has a personal time and that, just as external time is a continuum of instants, each personal time is a continuum of moments. ${ }^{13},{ }^{14}$ Likewise, just as an interval is a non-empty, non-scattered set of instants, a stretch is a non-empty, non-scattered set of moments. I assume that the same ternary temporal relation $\mathrm{R}$ - the 'after $\mathrm{a}, \mathrm{b}$ comes before $c^{\prime}$ relation - also holds among moments, and that the same duration properties that hold of intervals also hold of stretches. But I assume that no moment is an instant and hence that no stretch is an interval, and that only moments can be starting points or endpoints of stretches.

I invoke a primitive predicate, ' $x$ is a moment in the personal time of $y$ ', for the salient relation that holds between moments and objects. An object's personal time, as a whole, can then be defined as the set of moments-of-its-personal-time. Finally I assume that if $\mathrm{m}$ and $\mathrm{m}^{*}$ are moments and are connected by our ternary relation $\mathrm{R}^{15}$ then they are both moments in the personal time of some single object. I do not assume that moments of personal are sui generis entities or that the facts about the durations of stretches, or about the temporal relations between moments, are metaphysically fundamental. I leave these issues open here. (I would

\footnotetext{
${ }^{13}$ As far as I am aware, everything I say in this paper is consistent with the view that each personal time is a continuum of moments, and I find that view plausible. But the central arguments of the paper do not require the view or its necessitation. For example, one might follow Dainton (2008) and take it to be possible for there to be a person or other organism whose personal time is not a continuum but rather is the union of two separate, disconnected continua, each analogous to a line segment. Informally, such a person would lead two parallel lives. Nothing in this paper requires me to rule that out.

${ }^{14}$ Lewis (1976) does not explicitly address the question of whether there are such entities as moments of personal time and if so, what their nature might be. I suspect that he would prefer not to postulate such entities. However, Dainton (2008: 364-408) develops a theory of personal time that is built on Lewis's views but that does postulate moments of personal time. Horwich (1987: 115) postulates entities that he calls 'proper times' of a time traveler, in the context of a discussion of time travel and general relativity. It is clear that these so-called proper times are not instants of external time; they are not, for example, maximal spacelike hypersurfaces. Gilmore (2007b) postulates 'moments of proper time' in a similar context.

${ }^{15}$ I.e., if $\mathrm{m}, \mathrm{m} *$ and some $\mathrm{x}$ instantiate $\mathrm{R}$ in some order.
} 
welcome a reductionist theory of personal time, but I won't try to formulate such a theory here.)

As before, two special purpose technical terms will be useful. I will say that $x^{\prime}$ s personal lifespan is the (possibly gappy) set of moments of $x^{\prime}$ s personal time at which $x$ is alive, ${ }^{16}$ and I will say that $y$ is a lifestretch of $x$ if and only if $y$ is a maximal stretch of $x^{\prime}$ s personal time throughout which $x$ is alive - i.e., (i) $y$ is a subset of $x^{\prime}$ s personal time, (ii) $y$ is a stretch (hence non-gappy), (iii) $x$ is alive at each moment in $y$, and (iv) $y$ is not a subset of any other stretch at each moment in which $x$ is alive. So 'personal lifespan' is the personal time counterpart of 'lifespan', and 'lifestretch' is the personal time counterpart of 'life-period'. Personal lifespans can be gappy. Lifestretches cannot. Both are subsets of a thing's personal time, which I take to be a continumm, hence not gappy.

\subsection{Two False Starts}

My goal is to formulate a true and informative instance of the schema

Necessarily, for any $x$ and any $y, x$ dies at $y$ if and only if 17

Given the apparatus just introduced, the two most natural ways of filling in the blank are the following:

C2 $y$ is an endpoint of some lifestretch of $x$.

\footnotetext{
${ }^{16}$ Why might one take it to be possible for an organism to have a gappy personal lifespan? In note 10, I gave three reasons one might have for accepting the possibility of gappy (external) lifespans. The first two apply equally to the case of gappy personal lifespans. (1) Consider a tardigrade, call it 0 , that is alive for a year, then in cryptobiosis for a year, then alive for another year and non-existent thereafter. Unless no personal time elapses for $o$ while it is in cryptobiosis (a controversial claim, especially given that (i) spending time in cryptobiosis is biologically normal for tardigrades, and (ii) they do undergo some intrinsic changes while in that state), it follows that o has a gappy personal lifespan. The total personal time of o, let us suppose, is a continuum composed of three consecutive yearlong stretches, as follows: $\left(m_{1}, m_{2}\right]$, throughout which o is alive, $\left(m_{2}, m_{3}\right]$, throughout which o is cryptobiotic and not alive, and $\left(m_{3}, m_{4}\right]$, throughout which o is alive. In that case, o's personal lifespan would be the union of the first and third stretches, which is a gappy set. (2) Suppose that we people just are our bodies and that our bodies typically continue to exist for a while after we die (Feldman 1992, Thomson 2008). Suppose further that it is possible for a human body to die, then exist for a while as a corpse (during which time intrinsic changes are occurring in the corpse and causal processes are all running in the usual direction), and then return to life. Like the tardigrade, such a person's personal time would be made up of three stretches, such that the person is dead, not alive, throughout the middle stretch. The person would have a gappy personal lifespan; the given personal lifespan, though not the person's personal time, would exclude the middle stretch.

Since a person's personal lifespan is a possibly proper subset of that person's personal time, it might turn out that her personal lifespan is gappy despite the fact that her personal time is a non-gappy continuum.

${ }^{17}$ A more ambitious goal would be to formulate a real definition of the relation expressed by ' $x$ dies at $y$ ', in the sense targeted by Rosen (MS). Only a real definition of this relation would justify talk of having specified what death is or what it is for a thing to die a time. As I point out later, I suspect that my accounts of death and immortality can be converted into true real definitions with slight modifications. I focus on the schema in question (and its analogue in the case of immmortality) mainly for simplicity.
} 
there is some $z$ such that:

1. $z$ is an endpoint of a lifestretch of $x$, and

2. either (a) $y=z$ or (b) $y$ is an instant and $x$, at $z$, is present at $y$.

The problem with $\mathrm{C} 2$ is that, since only a moment can be the endpoint of a stretch, C2 yields the result that things can die only at moments of their personal time. Together with my assumption that no entity is both a moment and an instant, C2 entails that things do not die at instants of external time, which I take to be incorrect.

C3 solves this problem by appeal to a three-place, locative predicate 'object 0 , at moment $\mathrm{m}$ of its personal time, is present at instant $\mathrm{t}^{\prime}$. To get a better grasp on the relation this predicate is supposed to express, it may help to see how the relation holds in another case we have discussed, case 1 , involving Oscar. Let $t^{*}$ be an instant of external time later than $\mathrm{t}_{1}$ but earlier than $t_{2}$ in that case. Then Oscar is present at $t^{*}$ 'twice over': there are exactly two moments of Oscar's personal time at which he is present at $\mathrm{t}^{*}$. At the earlier moment, Oscar is 'oriented forward' in external time. At the later, Oscar is 'oriented backward' in external time. But for any person $p$ who is not a time traveler, the relation expressed by ' $p$, at $x$, is present at $y^{\prime}$ induces a one-to-one correspondence between the set of moments of $p^{\prime} s$ personal time and the set of instants at which $p$ exists (a correspondence which, by the way, preserves both topological and metrical temporal relations).

The idea behind $\mathrm{C} 3$, then, is to add a clause to the effect that if a thing $x$ dies at a moment $m$ of $x$ 's personal time, and if $x$, at $m$, is present at instant $t$, then $x$ counts as dying at $t$, not just at $\mathrm{m}$. The problem with $\mathrm{C} 3$ is that it makes dying at a moment a necessary condition for dying at an instant. This is in tension with the possibility of the case below. Say that a thing's external timespan is the set of instants at which it exists, and consider

Case 5: Harold lives from 1900 to 1995 and never travels in time. In 1995, he is struck by a meteorite and vaporized. His external timespan is the interval $\left(t_{1}, t_{2}\right)$, throughout which he is alive. His personal time mirrors his external timespan, both metrically and topologically. It has no earliest or latest member. Harold is alive at each moment of his personal time.

However, there is an instant, $t_{2}$, that bounds his (external) timespan on its later end (without being included in it): $t_{2}$ is the endpoint of the relevant interval. There is no corresponding moment of Harold's personal time; his personal time has no endpoint.

As applied to case 5, C3 says that Harold does not die at any moment of personal time or at any instant of external time. This is incorrect. True, Harold does not die at any moment, but he does in fact die at an instant, namely $\mathrm{t}_{2}{ }^{18}$

\footnotetext{
${ }^{18}$ Some philosophers will deny that there could ever be a fact of the matter as to whether a given organism has a topologically open (as opposed to a half open or closed) external timespan. Likewise for lifespans, personal lifespans, and total personal times. Call their view topological skepticism. Another group of philosophers will concede that there are, or could be, topological facts of the relevant sort, but will insist that no two organisms that differ only in whether their timespans, lifespans, personal lifespans, etc., are open (partially open, closed) can ever
} 


\section{Your Personal Limits}

The solution is to invoke what is, in effect, the notion of a limit. ${ }^{19}$ At no moment of his personal time is Harold present at $t_{2}$, the instant of his death. But, for some positive real number $n$, there is a final n-minute-long stretch of Harold's lifestretch; and, loosely speaking, by picking later and later moments in the relevant stretch, one can get Harold to be, and to remain, within any arbitrarily brief interval surrounding $t_{2}$. Here is a more precise and general statement of the idea:

C4 Necessarily, for any $x$ and any $y, x$ dies at $y$ if and only if there is some lifestretch $z$ of $x$ such that:

1. if there is an endpoint $m$ of $z$, then either $y=m$ or $y$ is an instant and $x$, at $m$, is present at $y$, and

2. if there is no endpoint of $z$, then for any neighborhood $\varepsilon$ of $y$, there is a final stretch $z_{\delta}$ of $z$ and some positive real number $n$ such that:

a. the duration-in-minutes of $z_{\delta}=n$, and

b. for any moment $m_{\delta}$ in $z_{\delta}$

i. there is an instant $t$ such that $x$, at $m_{\delta}$, is present at $t$, and

ii. for any instant $t$, if $x$, at $m_{\delta}$, is present at $t$, then $t$ is in $\varepsilon .{ }^{20}$

differ as to whether, or when, they die, or as to whether they are immortal. As a slogan: a mere topological difference never makes a mortal difference. Call this view topological insignificance.

Given the view that space and time, or spacetime, are continua of unextended instants and/or points, topological skepticism is implausible on its face. So, in the absence of any argument for topological skepticism, I am content to set it aside and explore the consequences of its negation.

As to topological insignificance, I feel its pull, and I have taken pains to accommodate what is right about it. I have, e.g., formulated $\mathrm{C} 1$ in such a way that that if $x$ has an external timespan of $\left[t_{0}, t_{1}\right)$, and if $y$ differs from $x$ only in having, as its external timespan, $\left[t_{0}, t_{1}\right]$, then $x$ dies at $t_{1}$ iff $y$ dies at $t_{1}$. Further, $I$ regard Case 5 , involving Harold, as a problem for C3 mainly because it shows that C3 generates gratuitous violations of topological insignificance.

However, it would be heavy-handed to insist at the outset that topological insignificance must turn out to be true without exception, and that this constraint must take priority over all other theoretical desiderata. At most, we should embrace a qualified principle: if theory $\mathrm{T}_{1}$ allows mere topological differences to make mortal differences in a wider range of cases than does $T_{2}$, then that fact constitutes an advantage of $T_{2}$ with respect to $T_{1}$, an advantage that might be overridden by other factors. Moreover, it shouldn't be surprising if topological differences made mortal differences in some exotic cases. If time or spacetime are continua, then presumably we should say that topological features are among the intrinsic features of a life; in which case it is not wildly implausible that some facts about death depend on them.

19 The notion I employ is modelled on, but not identical to, the notion of the limit of a function. First, I do not assume that the relation in question is a function: I leave open the possibility that for some object o and some moment $\mathrm{m}$ of its personal time, there are two different instants $\mathrm{t}$ and $\mathrm{t}^{*}$ such that: $\mathrm{o}$, at $\mathrm{m}$, is present at $\mathrm{t}$, and $o$, at $m$, is present at $t^{*}$. Second, the relata of the relation are not numbers.

${ }^{20}$ To convert C4 into a real definition of the relation expressed by ' $x$ dies at $y$ ' (in the sense of real definition targeted by Rosen (MS)), one might wish to restate $\mathrm{C} 4$ so that it avoided talk of any specific units, such a minutes. One might also wish to replace talk of sets with talk of pluralities or mereological sums. Since these issues are orthogonal to the central issues of the paper, I will leave the restatement to the reader. 
As I use the expression 'final stretch', the analogue of a circle (ordered by, say, clockwise arrows) does not have any final stretches. Nor does the analogue of anything that includes such a circle. But if $y$ is the analogue of an arc embedded within such a circle - e.g., the [9 o'clock, 3 o'clock] arc - then it has many final stretches, e.g., the [1 o'clock, 3 o'clock] arc and the [2 o'clock, 3 o'clock] arc. Aside from examples like these, a final stretch is just what one would expect. If a given personal time is topologically and metrically like the interval $[1,10]$, then it has many final stretches - e.g., one corresponding to $[5,10]$ - and all of its final stretches are finitely long. If a given personal time is topologically and metrically like the non-negative reals, then it too has many final stretches, but all of them are infinitely many years long. ${ }^{21}$

To say that $\varepsilon$ is a neighborhood of instant $y$ is to say that $\varepsilon$ is an open interval about $y$. In other words, it is to say that (i) $\varepsilon$ is an interval, (ii) $\varepsilon$ includes $y$, and (iii) for some $t$ and $t^{*}, \varepsilon^{\prime} s$ starting point is $t$, its endpoint is $t^{*}$, and it excludes them both; thus $\varepsilon=\left(t, t^{*}\right)$. This means that a neighborhood of $y$ must include continuum-many instants in addition to $y$ and must not have a first or a last instant. Topologically a neighborhood must be like the real line.

Since $\mathrm{C4}$ is my final account, I want to spend some time explaining it informally. According to $\mathrm{C} 4$, in order for a thing $\mathrm{x}$ to die at an instant or moment $\mathrm{y}, \mathrm{y}$ needs to be related in a certain way to a lifestretch $z$ of $x$. How? We can divide things up into two cases.

In the first case, the relevant lifestretch $z$ has an endpoint $m$, though $z$ does not necessarily include $m .^{22}$ In that case, $x$ dies at $m$ and also at any instant $t$ such that $x$, at $m$, is present at $t$. Notice that, in this first case, it does not matter whether the lifestretch $z$ has a final, finitely-many-minute-long stretch. If $z$ somehow manages to have an endpoint $\mathrm{m}$ despite not having such a final stretch (e.g., despite having an 'infinitely long future'), then $x$ nevertheless dies at $m$ and at any instant $t$ such that $x$, at $m$, is present at $t$.

In the second case, the lifestretch $z$ has no endpoint: it includes no final moment, and it is not even bounded by anything later than it. In this case - assuming that $z$ is $x$ 's only lifestretch - $x$ can die only at an instant, not at a moment. Moreover, in order for $x$ to die at an instant $y$, the lifestretch $z$ does need to have a final, finitely long stretch: $z$ can't be infinitely long in the direction of the future. This requirement is potentially controversial, so I argue for it in section 7.2 .

Finally, it is in the second case that the notion of a limit becomes relevant. Think of yourself as $\mathrm{x}$. Then, as you 'move forward' in your personal time, you (at least typically) change your location in external time. ${ }^{23}$ Now, in this second case, you count as dying at an instant $y$ if

\footnotetext{
${ }^{21}$ More formally: $x$ is a final stretch of $y$ if and only if (i) $x$ and $y$ are both stretches, (ii) $x$ is a subset of $y$, (iii) for any $m_{1}, m_{2}$, and $m_{3}$ in $x$, if $R\left(m_{1}, m_{2}, m_{3}\right)$ and $R\left(m_{2}, m_{3}, m_{1}\right)$, then for some $m^{*}$ not in $x, R\left(m_{3}, m^{*}, m_{1}\right)$, (iv) any endpoint of $\mathrm{x}$ is an endpoint of $\mathrm{y}$ and vice versa, and $(\mathrm{v})$ any endpoint that is included in $\mathrm{x}$ is included in $\mathrm{y}$ and vice versa. Clause (iii) ensures that final stretches never 'contain circles'. Clause (iv) ensures that if $x$ is a final stretch of $y$, then $x$ 'extends exactly as far into the future' as does $y$. Clause ( $v$ ) ensures that if $x$ is a final stretch of $y$, then $x$ never excludes an endpoint that is included in $y$.

${ }^{22}$ Some philosophers say that trees and even people often continue to exist for a while, as dead things, after they die. Likewise, some will say that a tree, or even a person, might die at a certain moment of personal time and yet have later moments of personal time at which it is present but dead.

${ }^{23}$ This is loose talk and can be spelled out in terms of the predicate 'at $x, y$ is present at $z$ '. Everything that I say in this paper is intended to be compatible with a static, tenseless, B-theory of time, together with an analogous theory of personal time.
} 
and only if, for any neighborhood $\varepsilon$ around y, no matter how 'brief', your lifestretch has a finitely long final stretch throughout which your associated locations in external time are all within $\varepsilon$.

This completes my informal explication of C4. At the beginning of this section, I explained how C4 would apply to case 5, involving Harold. That C4 also handles cases $1-4$ is straightforward and is best left to the reader. It is worth noting, though, that cases $1-4$ are not specified in full detail: certain facts about the personal times of the characters in those cases are left implicit or unsettled. I take it to have been implicit in those cases that the personal times of the characters are of finite duration. There are some topological questions about those cases that are left unsettled: e.g., is there a final moment of Oscar's personal time? But since Oscar ought to count as dying at $\mathrm{t} 1$ either way, and since $\mathrm{C} 4$ yields that verdict either way, there is no need to settle that question. Likewise for the other unsettled questions.

\section{Sorensen's Cases}

In section 1 I sketched versions of two cases that figure prominently in Sorensen (2005). They provide important tests for my account.

\subsection{Dilation}

The first test case is the easier. Here it is, stated more explicitly this time:

Case 6. Mary's first 94 years, 364 days, and 23 hours of personal time are lived in step with external time. Her final hour of personal time is stretched out over infinitely many years of external time: 30 minutes of external time for the first 30 minutes of personal time, another 30 minutes of external time for the subsequent 15 minutes of personal time, another 30 minutes of external time for the subsequent $7 \frac{1}{2}$ minutes of personal time, and so on. Mary has a first moment of her personal time but no final moment, and she is alive at all such moments. Her personal time is exactly 95 years in duration. With regard to external time, the first instant at which she exists is $t$, and she exists at all later instants. She is alive at each instant at which she exists.

Two questions are relevant.

First, does Mary die at any moment? It seems to me that the correct answer is 'No'. Although there is a final year of her personal time, there is no final moment. At each moment (after the first), she is in the midst of a lifestretch and has more life left to live. To its credit, C4 yields this verdict. Since Mary is alive at each moment of her personal time and since there is no final such moment, $\mathrm{C} 4$ tells us that she does not die at any moment.

Second, does Mary die at any instant? Here again the correct answer is 'No', and the justification is, if anything, even more compelling. Not only does Mary's life have no final instant, it has no final year in external time. Granted, this fact by itself doesn't entail that she never dies. In the circular time of case 4, David is alive at every instant, and his external lifespan has no final year, and yet he dies at instant $t_{2}$ anyway, because, as he approaches his finite maximum age in personal time, he gets, and stays, within every neighborhood of $t_{2}$. But there is no such 'limit' in Mary's case. At no instant of external time will one find the end of Mary's life. 
So far as Mary is concerned, all one ever finds is 'the continuation' of a life. For what it's worth, I suspect that Sorenson would agree that Mary does not die. He claims that (his version of) Mary is immortal.

Here again C4 delivers the right result. Since Mary is alive at every moment of her personal time and since there is no last such moment, she doesn't die at any moment. So, in order for her to die at an instant, there needs to be the relevant sort of limit: an instant every neighborhood of which she eventually stays within as she 'moves forward' in her personal time. But there is no such limit. So C4 has passed the easier of its two tests from Sorensen.

\subsection{Contraction}

The harder test comes in the form of

Case 7. John's first 94 years, 364 days, and 23 hours of personal time are lived in step with external time. Then, at instant $t$, more and more of his personal time starts to be packed into the final hour of his external timespan. One whole year of his personal time gets packed into the first 30 minutes of external time post-t, another year of personal time in the next 15 minutes of external time, yet another year of personal time in the subsequent $7 \frac{1}{2}$ minutes of external time, and so on. John's external timespan is the 95year-long interval $\left[\mathrm{t}_{1}, \mathrm{t}_{2}\right)$, and he is alive at each of the instants in this interval and at no others. His personal time has a first moment but no final moment, and it is infinitely many years long, with no finitely long final stretch. He is alive at each moment of his personal time.

Again, two questions are relevant.

First, does John die at any moment? Clearly the answer is 'No'. John is alive at every moment of his personal time, and his personal time has no endpoint or final year. From the perspective of his personal time, his life is infinitely long and has no end. C4 gets this question right. It tells us that John doesn't die at any moment.

Second, does John die at any instant? Here there is controversy. C4 yields the verdict that John does not die at any instant, since clause $2 a$ is not satisfied: there is no finitely long final stretch of John's personal time. To 'get John arbitrarily close' to $t_{2}$, one needs use some infinitely long final stretch of his personal time. In my view C4's verdict is correct, for reasons that I will explain. ${ }^{24}$

But Sorensen would say that John dies at $\mathrm{t}_{2} \cdot{ }^{25}$ How might one motivate Sorensen's view? I'll allow my interlocutor three tries at supplying such a motivation.

\footnotetext{
${ }^{24}$ I suspect that Tipler would agree. Although he does not explicitly frame the issue in terms of the concept of death, he does claim that 'life continues forever' (1994: 132) in cases like John's. These cases form the centerpiece of his book, The Physics of Immortality. He writes that

although a [spatially finite] closed universe exists for only a finite proper [external] time, it nevertheless could exist for an infinite subjective [personal] time, which is the measure of time that is significant for living beings (1994: 136).

As Tipler notes (1994: 108), similar ideas are defended by Milne (1952).

${ }^{25}$ Sorensen's primary interest in these cases is axiological, not metaphysical, but he does make some metaphysical claims about them in passing. In his discussion of (his version of) case 7, he writes that 'if the
} 


\subsubsection{John dies at $t_{2}$ : first try}

[The interlocutor speaks.] Just as personal time is not real time, 'personal immortality' of the sort possessed by John in case 7 is not real immortality. To be (really) immortal, one must have no final year with respect to external time, not merely with respect to one's own personal time. So John is not immortal. Further, if one is not immortal, and if one's life comes to an end at a certain instant of external time and one never exists again thereafter, then one (really) dies at that instant, even if one experiences infinitely many years of personal time, with no final year, in some interval leading up to that instant. Since that is what happens to John at $t_{2}$, he dies then.

Reply. If there is an argument to be extracted from the speech above, it is the following:

(i) If a thing $\mathrm{x}$ is alive throughout some interval that ends at instant $t$ and $\mathrm{x}$ does not exist at any instant thereafter, then $x$ dies at $t$.

(ii) John is alive throughout some interval that ends at instant $t_{2}$.

(iii) John does not exist at any instant after $t_{2}$.

(iv) So, John dies at $t_{2}$.

But line (i) has already been shown to be false on independent grounds: cases 1 and 2 are counterexamples. ${ }^{26}$ In case 1 , Oscar is alive throughout an interval that ends at $t_{2}$ and he doesn't exist at later times; and yet, contrary to (i), he doesn't die at $t_{2}$. Rather, he merely 'reverses direction in time' then. Similar claims are true of Maria in case 2.

So one main theme of the speech above - that the notion of personal time has no role to play in an account of what it is to die - is false. To say what it is for a thing to die at an instant of external time - and in particular, to say why Oscar and Maria don't count as dying at the relevant instants of external time, despite the fact that their external lifespans end then and they never exist again with respect to external time - one already needs to appeal to the notion of personal time. Oscar really dies at $t_{1}$, and not $t_{2}$, despite the fact that $t_{2}$, not $t_{1}$, is the endpoint of his lifespan in real time. Although personal time is not real time, personal time plays a role in the correct account of what real death is.

pseudo-immortal discovers his veiled mortality, then he knows he will be dead in two minutes' (2005: 123, italics original). I take this to indicate that, according to Sorensen: (i) John is mortal, not immortal, (ii) John is dead at $\mathrm{t}_{2}$ and at all times thereafter, and (iii) John dies at $\mathrm{t}_{2}$.

${ }^{26}$ One need not resort to time travel cases to find a counterexample to (i). Suppose that an amoeba divides into two new amoebas at $t$. The amoeba is alive throughout some interval that ends at $t$ and does not exist at $t$ or afterward. But, contrary to (i), it doesn't die at t, and it isn't dead then or afterward. It lived, then it divided and ceased to exist without dying, and thereafter it was neither alive nor dead. Why not say something similar about John? 


\subsubsection{John dies at $t_{2}$ : second try}

[The interlocutor speaks.] I concede that a correct account of death needs to invoke both the notion of personal time and the notion of a limit, in basically the same way that C4 does. But C4, which speaks of final stretches and requires that they be of finite duration, is unnecessarily complicated. A simpler principle avoids these notions but yields the same verdicts as $\mathrm{C} 4$ when applied to all the clear cases. The simpler principle is:

C5 Necessarily, for any $x$ and any $y, x$ dies at $y$ if and only if there is some lifestretch $z$ of $x$ such that:

1. if there is an endpoint $m$ of $z$, then either $y=m$ or $y$ is an instant and $x$, at $m$, is present at $y$, and

2. if there is no endpoint of $z$, then for any neighborhood $\varepsilon$ of $y$, there is a moment $m_{\delta}$ in $z$ such that: for any $m_{1}$ and $m_{2}$ both in $z$, if, after $m_{\delta}$, $m_{1}$ comes before $m_{2}$ (i.e., if $R\left(m_{\delta}, m_{1}, m_{2}\right)$ ), then

a. there is an instant $t$ such that $x$, at $m_{2}$, is present at $t$, and

b. for any instant $t$, if $x$, at $m_{2}$, is present at $t$, then $t$ is in $\varepsilon$.

As applied to case 7 , this principle says that John dies at $t_{2}$ because - roughly - for any neighborhood of $t_{2}$ you pick, you can get John to get and stay within it just by going far enough forward in his life-stretch. Since C5 gets all the clear cases right and is simpler than C4, we should defer to it with regard to case 7.

Reply. C5 does get cases $1-6$ right. But there are other clear cases, not yet considered, that it gets wrong. I want to start by discussing two preliminary cases as warm-ups for the counterexample case.

Case 8. Spacetime has a circular temporal dimension. The circumference of the circle is just 30 seconds in duration. Joan is an adult human being (or human-like entity) who inhabits this spacetime. Her personal time matches external time both topologically and metrically: it forms a circle 30 seconds in duration and has no beginning or end. She is alive and conscious throughout her personal time. She rides a carousel that makes one full rotation every 15 seconds. ${ }^{27}$

\footnotetext{
${ }^{27}$ Sorabji writes, "I believe that circular time is in principle possible. . . In principle it would have been possible for there to be a universe with a forty-year time cycle. In such a universe, we might dwindle and regrow, rather than die..." (2006: 326). Sorabji interprets a passage from the pseudo-Aristotelian Problemata as alluding to this same scenario. The passage considers whether time could be circular, and it includes the sentence, "In fact, Alcmaeon says that people die simply because they are not able to join beginning to end" (2006: 329). The possibility of entities with circular personal times (in worlds in which external time is circular) is defended in Gilmore (2007b) and (2010). Circular personal time is also mentioned by Dainton (2008: 407-408).
} 


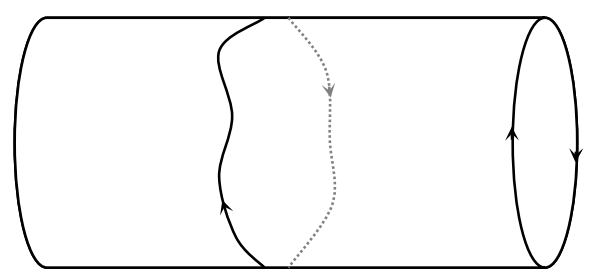

In some ways, case 8 is like case 4 , involving David, the old man who dies while sailing. But in case 4 , the duration of time's circle is much shorter, and unlike David, Joan has a circular life. ${ }^{28}$ In any event, I take it to be clear that in case 8, Joan does not die at all - not at any instant of external time, and not at any moment of her personal time. Our second warm-up case is

Case 9. D. C. Williams writes that "it is conceivable, indeed, that a single whole human life should lie thwartwise of the manifold, with its belly plump in time, its birth at the east and its death in the west, and its conscious stream perhaps running alongside somebody's garden path" (1967: 112). If the organism in question were spatially twodimensional, its entire spacetime path could be confined to an instantaneous, threedimensional spacetime region. So let $B^{2}$ be such an organism. Its personal time, which is the interval $\left[\mathrm{m}, \mathrm{m}^{*}\right]$, has a first moment and a last, and it is 95 years in duration. $\mathrm{B}^{2}$ is present at only a single instant of external time, $t$, though at each moment of its personal time it has a different location in space.

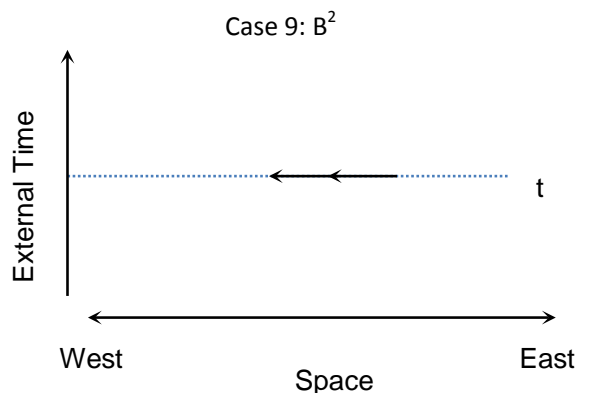

I assume that in case $9, B^{2}$ dies at moment $m^{*}$ of its personal time, and at instant $t$ of external time.

The groundwork is now in place for my counterexample to C5. It combines aspects of the previous two cases:

\footnotetext{
${ }^{28}$ I have made no effort to describe the physiological details underlying case 8 . I don't claim that the case is physically or biologically possible, but I am confident that if circular time is metaphysically possible, then so is some case relevantly like case 8 and that, with enough effort, the details could be filled in. The fact that Joan is a conscious human being - as opposed to, say, a bacterium - is irrelevant.
} 
Case 10. Doris is a spatially two-dimensional organism whose entire life is confined to a single instant, t. At each moment of her personal time, she is exactly located at one or another two-dimensional, disc-shaped region of spacetime, all within t. Doris's personal time is 30 seconds long. However, whereas $B^{2}$ had a line-like personal time, Doris has a circular personal time. In this respect she is like Joan. Doris's spacetime path is an instantaneous, three-dimensional, torus-shaped region. She is alive and conscious at each moment of her personal time.

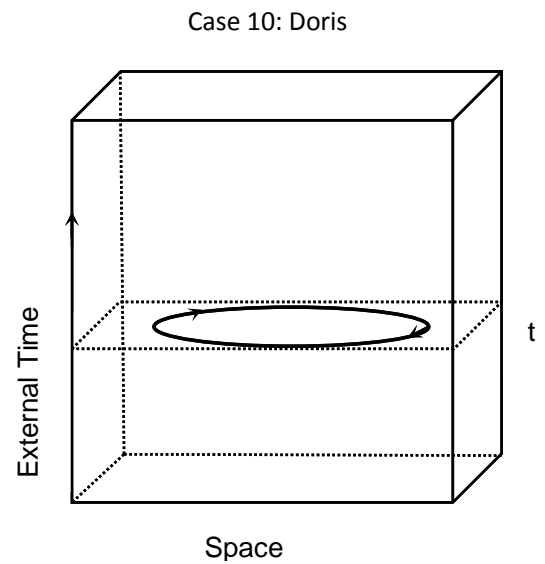

I take it to be clear that in case 10, Doris doesn't die at any moment or instant. Doris no more dies than Joan does. But notice that if C5 is true, then Doris dies at instant t. She has only one lifestretch, which is the entirety of her personal time. And that lifestretch has no endpoint. Further, it is true - almost vacuously - that for any neighborhood of $t$, one can find a moment $m_{\delta}$ of her personal time such that, at each 'later' moment, her associated location in external time is within that neighborhood. After all, at each moment of her personal time, her corresponding location in external time is $t$ itself, which is in all of its own neighborhoods! So according to $\mathrm{C} 5$ she dies at t. So $\mathrm{C} 5$ is false.

\subsubsection{John dies at $t_{2}$ : third and final try}

[The interlocutor speaks.] I grant that Doris is a counterexample to C5. But here is principle that handles Doris's case and yet is still simpler than C4:

C6 Necessarily, for any $x$ and any $y, x$ dies at $y$ if and only if there is some lifestretch $z$ of $x$ such that

1. if there is an endpoint $m$ of $z$, then either $y=m$ or $y$ is an instant and $x$, at $m$, is present at $y$, and

2. if there is no endpoint of $z$, then for any neighborhood $\varepsilon$ of $y$, there is a final stretch $z^{*}$ of $z$ such that, for any moment $m_{\delta}$ in $z^{*}$ : 
a. there is an instant $t$ such that $x$, at $m_{\delta}$, is present at $t$, and

b. for any instant $t$, if $x$, at $m_{\delta}$, is present at $t$, then $t$ is in $\varepsilon$.

Unlike C5, this principle requires that if $x^{\prime} s$ lifestretch $z$ has no endpoint, then $z$ must at least have a final stretch (which Doris's does not), if $x$ is to die at an instant t. Doris's lifestretch does not have a final stretch because it is circular, so C6 tells us, correctly, that Doris does not die. And unlike C4, C6 says nothing about there being a final stretch of finite duration.

Since $\mathrm{C} 6$ yields the correct verdicts as applied to all the clear cases so far considered, and since it is simpler than C4, we should defer to its verdict on case 7, involving John. John's lifestretch does have a final stretch; and as one moves forward in it, John gets and stays within every neighborhood of $t_{2}$. So C6 counts John as dying at $t_{2}$.

Reply. There are counterexamples to $\mathrm{C} 6$ as well. Two of them arise from

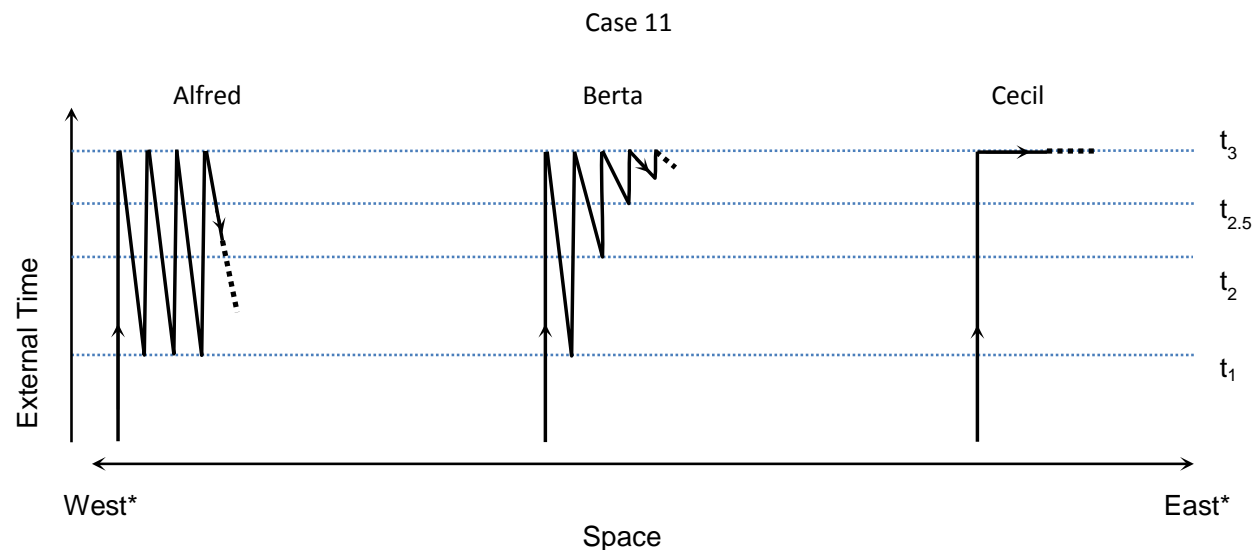

Case 11. Alfred, Berta, and Cecil live normal lives until age 18. All three have personal times that are line-like and infinitely long, having no endpoint and no finitely long final stretch; and all three of them are alive throughout their personal times. At instant $t_{3}$ in 2015, their personal times come apart from external time, in different ways. Alfred and Berta reverse direction in external time, whereas Cecil 'flat-lines', in the manner of $\mathrm{B}^{2}$ : the remainder of his life is confined to $t_{3}$. He has a constant 'personal time velocity': he 'moves' in a certain direction -call it 'eastward*' - at a rate of 5 feet per 20 years of his personal time. ${ }^{29}$ The portion of his spacetime path confined to $t_{3}$ is infinitely many miles long.

Alfred and Berta spend the next 10 years of their personal times traveling back to instant $t$ in 2005 and the subsequent 10 years of their personal times traveling forward in time back to $t_{3}$. Upon reaching $t_{3}$ again, Alfred reverses direction in time and spends the next 10 years of his personal time travelling back to $t_{1}$. He continues on in this manner for the remainder of his personal time. At each of his visits to $t_{3}$ (aside

\footnotetext{
${ }^{29}$ Assume that one does not go in circles by going eastward*.
} 
from the first), he is 5 feet to the east* of himself on his previous visit. Likewise for his visits to $t_{1}$.

When Berta reaches $t_{3}$ for her second time and reverses course, she spends the next 10 years of her personal time working her way back to instant $t_{2}$ in 2010 , only five years earlier than $t_{3}$. She reverses direction in time and spends the next 10 years of her personal time traveling to $t_{3}$, where she reverses course and spends the next 10 years of her personal time traveling back to instant time $t_{2.5}$, just $2 \frac{1}{2}$ years earlier than $t_{3}$. She continues on this manner for the remainder of her personal time. Each of her trips backwards takes 10 years of her personal time (one-way), but each, aside from the first, takes her back only half as far as the previous one. Each time she reaches $t$, aside from the first, she is 5 feet to the east* of herself on her previous visit.

If $\mathrm{C} 6$ is true, then Berta and Cecil die but Alfred does not. As one moves forward in Berta's personal time, her location in external time gets and stays within any neighborhood of $t_{3}$. This is also true of Cecil (in a less interesting way). But not so for Alfred, since he keeps going back to $t_{1}, 10$ years prior to $t_{3}$, once every twenty years of his personal time. So, according to C6, Berta and Cecil die at $t_{3}$ (and then only), whereas Alfred does not die at any instant or moment.

But in fact, none of them dies at any instant. It's clear that Alfred doesn't die at $t_{3}$, and C6 agrees. But it's also clear, I hope, that Alfred does not differ from Berta or Cecil with respect to dying at $t_{3}$. What, apart from a desire to preserve $C 6$, could motivate one to say that Alfred but not Berta dies at $t_{3}$ ? They both bounce back and forth between $t_{3}$ and earlier times forever, they both always have an infinite personal future to look forward to, and they both have infinitely many spatial locations at $t_{3}$, extending eastward* infinitely far. That Berta's bounces into past get ever smaller in the given manner is irrelevant to whether she dies. If I am right about Berta, then C6 is false, regardless of how the case of Cecil ought to be described.

But Cecil is a persuasive counterexample to $\mathrm{C} 6$ in his own right. Cecil is to an ordinary immortal what Doris is to Joan. Joan inhabits a universe in which external time is circular, and she herself has a circular personal time and never dies. Doris's entire life occurs at a single instant, but despite that, she never dies, since her personal time is just like Joan's. Doris is the 'thwartwise' version of Joan, to borrow Williams's term. Now consider an ordinary immortal - a being who is born, who exists at all later instants and throughout an open interval of infinitely many years, and whose personal time never falls out of step with external time. Cecil, setting his first 18 years aside, is just the thwartwise version of the ordinary immortal. It's hard to see why this 'thwartwise' operation would preserve deathlessness in the move from Joan to Doris but not in the move from the ordinary immortal to Cecil. So, given that the ordinary immortal never dies, it's plausible that the same is true of Cecil. This constitutes an independent counterexample to $\mathrm{C6}$.

\subsubsection{Summary}

Joan, Doris, Alfred, Berta, and Cecil are all alike in being deathless - in not dying at any moment or instant. What do they all have in common in virtue of which they are deathless? 
One thing they all have in common is that they lack lifestretches with final moments or finitely long final stretches that eventually keep them arbitrarily close to a certain instant. The lifestretches of Joan and Doris, though finite in length, are circular and have no final moment or final stretch at all. The lifestretches of Alfred, Berta, and Cecil, though in possession of final stretches, have no final moments or finitely long final stretches. This is all to the credit of C4, which is framed in just these terms. Indeed, it seems to me that C4 is the simplest, most natural principle that handles all of the clear cases so far considered.

Now let me return to Sorensen's case of the 'pseudo-immortal', which provoked this discussion in the first place. Recall that in case 7, John packs infinitely many years of his personal time into a finitely long external interval leading up to instant $t_{2}$. His lifestretch gets him arbitrarily close to $t_{2}$ but it has no final moment or finitely long final stretch. Does John die at $t_{2}$ ? John is relevantly similar to Berta and Cecil. Given that they don't die, it's plausible that John doesn't either. This is the verdict that C4 delivers. It passes the test. ${ }^{30}$

\section{Death and Successive Infinite Epochs}

Lewis (1986: 72) embraces the possibility of worlds in which time is made up of two disjoint epochs, each with an infinite future, such that one of them is immediately after the other. ${ }^{31}$ In such a world, each instant in the second epoch is infinitely many years later than each instant in the first epoch. Phillip Bricker (1985 MS) argues in detail for this possibility and, moreover, for the possibility of a person who lives through two such epochs (and whose personal time matches external time).

Bricker is interested in the desirability of various forms of immortality, not in the nature of death per se. But his claim raises an interesting question about death: if a person were alive throughout the first epoch but did not exist at all during the second epoch, would she die? To make the question more precise, consider

Case 12. Time is composed of two disjoint epochs, the second of which immediately follows the first. Each epoch has a first instant and a first year but no final instant or final year. The adjacent, non-overlapping, year-long intervals of which time is composed correspond to the numbers in the sequence

$$
1,3,5, \ldots 2,4,6, \ldots
$$

The odd numbers correspond to the years in the first epoch, the evens to the years in the second. There is a first year, which corresponds to the number 1 above, there is a second year, which corresponds to the number 3 above, and so on. Then, after all such

\footnotetext{
${ }^{30}$ Consider a variant of case 7 , call it case $7^{*}$, in which there is a final moment $m^{*}$ of John's lifestretch, where $m^{*}$ is also the final moment of John's personal time as whole. Moment $\mathrm{m}^{*}$ is infinitely many years later than any other moment of John's personal time, and (let me stipulate) at $\mathrm{m}^{*}$, John is alive and present at $\mathrm{t}_{2}$. Otherwise case $7^{*}$ is as similar as possible to case 7 . According to $C 4$, John dies at $t_{2}$ in case $7^{*}$. So, since C4 tells us that John dies at $t_{2}$ in case 7 but not in case $7^{*}$, despite the fact that these cases differ 'only topologically', C4 violates the principle I called topological insignificance in note 18. I find C4's verdicts about these cases to be more plausible than topological insignificance, so I do not see this point as a problem for C4.

31 More specifically, Lewis endorses the possibility that each of the two epochs has an infinite past and an infinite future: "Time might have the metric structure not of the real line, but of two copies of the real line laid end to end. . . Each epoch would have infinite duration, no beginning, and no end" (1986: 72). Presumably he would also endorse the possibility of case 12 in the main text below.
} 
intervals, there is a first year of the second epoch, which corresponds to the number 2 above, and then there is second such year, which corresponds the number 4 above, and so on. Each instant in the second epoch is infinitely many years later than any instant in the first epoch.

Luis is alive throughout the first epoch but does not exist, and hence is not alive, at any instant in the second epoch. Luis does not travel in time. His personal time matches the first epoch in external time. Once he reaches adulthood, he rises each morning, goes to work, then returns home in the evening, taking weekends and holidays off, ad infinitum.

Does Luis die? If so, then he dies at $t_{2}$, the first instant of the second epoch, and then only, for obvious reasons. He doesn't die at any moment of his personal time, since his lifestretch has no endpoint.

The analogy between Luis and John should be evident. Luis's case is what would result if one started with John's case, held fixed all the facts about John's personal time and all the facts about external time at $t_{2}$ and thereafter, and then stretched out external time in the interval leading up to $t_{2}$, so as to make that interval match John's infinitely long personal time. Not surprisingly, C4 and C6 disagree over Luis's case, just as they disagree over John's. According to C6, John and Luis both die. ${ }^{32}$ According to C4, neither dies. I lack firm pre-theoretical beliefs about Luis's case, so I am content to defer to C4.

My considered view about Luis, then, is that he never dies. Further, I hold that he is immortal, despite the fact that there are times after his lifespan, times at which he is not present, much less alive. ${ }^{33}$ More on this in section 10.

\section{Objection: Death and Resurrection}

Philip Swenson and Eric Yang have posed an objection to C4. Their objection arises from

Case 13. Lydia lives a normal life until, at instant $t_{1}$, she is vaporized by a meteorite. She is alive throughout a 95-year-long interval leading up to $t_{1}$ but does not exist at $t_{1}$ or at any instant in the next thousand-year-long interval. At the endpoint of this interval, $t_{2}$, God sees to it that Lydia exists, and is alive, once again. ${ }^{34}$ She is alive at $t_{2}$ and throughout the infinitely many years thereafter. Although her external lifespan is scattered, her personal lifespan is not. Her personal time divides into two adjacent stretches. The first stretch is 95 years long and has no final moment. The second stretch has a first moment, $m_{2}$, it's infinitely many years long, and it immediately follows the first stretch. (At $m_{2}$, Lydia is present at $t_{2}$.) Lydia is alive at each moment of her personal time, which is infinitely long and has no final moment or final year.

\footnotetext{
${ }^{32}$ If the notion of a limit at work in C4 and $\mathrm{C} 6$ had been defined in metrical terms ('x gets and eventually stays arbitrarily close to $y$ ') as opposed to topological terms (' $x$ gets and eventually stays within any neighborhood of $y^{\prime}$ ), the symmetry between the cases of John and Luis would be broken. John does get and eventually stay arbitrarily close to the relevant instant in his case, but Luis does not: Luis's location in external time is always infinitely many years earlier than $\mathrm{t} 2$. But Luis does get and eventually stay within every neighborhood of $\mathrm{t} 2$.

${ }^{33}$ My view harmonizes with that of Smith (1989: 316), who holds that any object like Luis counts as permanent.

${ }^{34}$ For view of resurrection that would permit this aspect of the case, see Merricks (2009).
} 
Here is the objection:

(i) Lydia dies at $t_{1}$.

(ii) If C4 is true, then Lydia does not die at $t_{1}$.

(iii) So, $\mathrm{C} 4$ is not true.

(i) is motivated by the fact that Lydia gets vaporized by a meteorite at $t_{1}$ and ceases to be alive then. (ii) is motivated by the fact that Lydia's personal time is a single, infinitely long (nonscattered) lifestretch, without a final moment or a final year. As applied to this case, C4 says that Lydia does not die at any instant or moment, hence not at $t_{1}$.

Reply. I deny (i). Like Tanya in case 3, Lydia does not die at $\mathrm{t}_{1}$, she merely jumps forward in time then. The mechanism that underlies this jump - involving a meteorite at one end and an act of God at the other - does not fit the usual image of time travel. But if we hold the detailed description of the case fixed, it clearly counts as involving a jump forward in time.

Moreover, if we are tempted to say that Lydia dies at $t_{1}$, we should also be tempted to say that about Tanya. After all, something quite violent happens to Tanya at $t_{1}$ : whatever the process may be that acts upon her, it somehow causes her to cease to be alive, and even to pop out of existence, at $t_{1}$. She too begins to exist again only after a period of non-existence. So, given that Tanya does not die at $t_{1}$ in her case, it is reasonable to say the same about Lydia in hers. Even if this strikes some readers as a cost, it should hardly be seen as a deal-breaker.

Finally, it is worth noting how small a departure from case 13 is needed to get a case that does involve something that dies at $t_{1}$. First, even as the case is currently written, if (with Baker (2000), e.g.) we are willing to deny that Lydia is identical to her body, we are free to say that her body dies at $t_{1}$, provided that her body does not jump into the future just as she does. Second, we might consider a case in which there is a 1000-year-long stretch $s$ of Lydia's personal time that intervenes between her first 95 years of personal time and $\mathrm{m}_{2}$. Suppose that each moment $\mathrm{m}$ in $\mathrm{s}$ is such that, at $\mathrm{m}$, Lydia is not present at any instant and is not alive. ${ }^{35}$ In that case, Lydia dies at $t_{1}$ and, if the intervening stretch is long enough, she does not count as jumping forward in time. Third, if one is willing to allow cases in which a thing has a personal time that is not a continuum, one might consider a case in which Lydia's personal time is the union of two disconnected, temporally unrelated stretches: the 95-year-long stretch mentioned earlier, and an infinitely long stretch whose starting point is $\mathrm{m}_{2}{ }^{36}$ In this case, too,

\footnotetext{
${ }^{35}$ In more detail: for each moment in the first 95 years of her personal time, Lydia has, relative to that moment, a location in space and a location in external time, but for the next 1 year of her personal time, Lydia is not alive and exists 'outside space and outside external time'. For each moment $m$ in that 96 th year of her personal time, there is no instant of external time $t$ such that: at $m$, Lydia is present at $t$. Further, we can suppose that (i) the endpoint of that 96th year of her personal time is the moment $m_{2}$, that (ii) $m_{2}$ is not included in that year, and that (iii) at $m_{2}$, Lydia is present at $t_{2}$. (I take no stand on whether this case is metaphysically possible.)

${ }^{36}$ In virtue of what, one might wonder, are the two stretches of personal time temporally unrelated? Various answers could be given. Perhaps, e.g., it is because Lydia's intrinsic condition at $m_{2}$ at $t_{2}$ is not immanently caused by her intrinsic condition in any of the instants leading up to the end of the other stretch.
} 
Lydia dies at $t_{1}$. If one is initially inclined to say that Lydia dies at $t_{1}$ in case 13 , perhaps this is partially due to a failure to distinguish case 13 from the variations I have just described.

\section{Immortality}

I have given an account of what it is to die at an instant or moment. The target of that account is the two-place relation expressed by ' $x$ dies at $y$ '. My target in this section is immortality, a property expressed by ' $x$ is immortal'.

I take it that mortality and immortality are contraries, not contradictories. So, if mortality were the property being something that dies, ${ }^{37}$ it wouldn't follow that immortality is just the negation of that property - being something that does not die. This is good, since my wallet, despite never dying, is not immortal.

What is it for a thing to be immortal? How can the blank in the following schema be filled in so as to make the resulting sentence true and informative?

IM Necessarily, for any $x, x$ is immortal if and only if

Here are some candidates:

IM1 $\mathrm{x}$ is alive at some instant and does not die at any instant.

IM2 $\quad x$ is alive at some instant and at all later ${ }^{38}$ instants.

IM3 $\quad x$ is alive throughout some interval that is infinitely many years long.

IM4 $x$ is alive throughout some interval $y$ such that (i) $y$ has a final segment ${ }^{39}$ and (ii) every final segment of $y$ is infinitely many years long.

IM5 $\quad x$ is alive at some instant, at all later instants, and throughout some interval $y$ such that (i) y has a final segment and (ii) every final segment of $y$ is infinitely many years long.

IM6 $\quad \mathrm{x}$ is alive throughout some interval that has no finitely long final segment.

IM1 fails in the cases of deathless biological fission mentioned in section 3.2. Consider an amoeba that lives for a while then ceases to exist by dividing into two new amoebas. It lives and never dies but is not immortal. IM2 fails in certain cases involving circular time, such as case 4. In that case, David is alive at an instant and at all later instants - he is alive at every instant but he has a finitely long life, eventually dies, and is not immortal. IM3 fails in cases in which a person's life-period has an infinitely long past but a finitely long future. Perhaps, e.g., Treebeard has already been alive for infinitely many years but will die in one week and never live again. Then despite being alive throughout some interval that is infinitely many years long, he is not immortal. IM4 correctly classifies David and Treebeard as not being immortal, but incorrectly classifies Joan (who has a finitely long, circular personal time) in case 8 as not being immortal. IM5 has the same problem. Further, it classifies Luis as not being immortal, which I believe to

\footnotetext{
37 Which it is not. It will emerge that, on my account of immortality, things that die can still be immortal. Despite my title, I have no account of mortality to offer.

${ }^{38}$ In terms of $R: x$ is alive at some instant $t$ and at every instant $t_{2}$ such that, for some instant $t_{1}, R\left(t, t_{1}, t_{2}\right)$.

${ }^{39}$ A final segment is to external time what a final stretch is to personal time. The formal definition is parallel.
} 
be incorrect. IM6 correctly classifies Joan and Luis as immortal but incorrectly classifies David as immortal.

\subsection{An Account}

An adequate account of immortality needs to invoke personal time. But this by itself doesn't get us very far. One should not, e.g., say that to be immortal is to have an infinitely long lifestretch, since that would incorrectly classify Treebeard, in the above case, as immortal. I propose this: you are immortal if and only if, for some positive real number, you are always (at every moment of your personal time) in a position to look forward to at least that many more personal minutes of life. More formally:

IM7 there is some positive real number $n$ such that for any moment $m$ of $x$ 's personal time, there is a set $u$ such that (i) $u=\left\{m_{2}\right.$ : for some $m_{1}$, after $m, m_{1}$ comes before $m_{2}$, i.e., $R\left(m, m_{1}, m_{2}\right)$, and $x$ is alive at $\left.m_{2}\right\}$, and (ii) u's duration-in-minutes is greater than or equal to $n .^{40}$

In other words, to be immortal is to be such that it never happens to you that what is left of your life - the portion of your life in your personal future - gets arbitrarily brief.

It follows that anyone who has a circular personal time, and who is alive throughout some stretch of that circle that lasts for some positive real number of minutes, is immortal. Likewise, anyone who alternates between being alive for a minute of personal time, then dead for a minute of personal time, and so on ad infinitum, is immortal. And anyone whose lifestretch is like Joan's, John's, or Luis's is immortal. ${ }^{41}$ For a person of any of these kinds, there is a positive 'minimum threshold' duration such that, with respect to her personal time, she will always have at least that much more life left to live.

\subsection{Consequences}

Let me mention three interesting consequences of the account. First, consider Luisa, who inhabits the same universe as Luis: the Bricker-style, two-epoch universe. Her life is like Luis's throughout the first epoch, but she outlives Luis and survives into the second epoch. Then things go sour. In the second year of the second epoch, she is struck and killed by a meteorite and never lives or exists again. Her personal time matches her external timespan. Is Luisa immortal? I say that she is not, despite the fact that she outlives Luis, who is immortal. Luisa's problem is that there is no positive 'minimum threshold' such that she always has at least that much personal time left to live. At any moment of Luis's personal time, by contrast, he has infinitely many years of his life left.

Second, consider Carlos, who inhabits a world in which time is circular. Like David, Carlos has a personal time with a first moment and a first year, and his personal time is only

\footnotetext{
${ }^{40}$ As with $\mathrm{C} 4$, to convert IM7 into a real definition of the property expressed by ' $\mathrm{x}$ is immortal', one might wish to restate IM7 so that it avoided talk of any specific units, such a minutes. One might also wish to replace talk of sets with talk of pluralities or mereological sums. I leave this restatement to the reader.

${ }^{41}$ As applied to case $7^{*}$, from note 30, IM7 tells us that John is not immortal, which I take to be correct.
} 
finitely long. This might make it sound as though Carlos is doomed to mortality. But, so far as my account goes, Carlos might still be immortal.

Note that there is a controversy about whether a person would survive a process of fission, in which her body divided, amoeba-style, into what would appear to be two human bodies, each psychologically, spatiotemporally, and materially continuous with the original. (See Demarest (2015) for a recent contribution to, and overview of, this debate.) Those who hold that a person would survive such a process include Lewis (1983) and Dainton (2008). Lewis defends a double-occupancy account of such cases, according to which they involve two persons who are spatially co-located prior to the fission but who cease to be co-located when the fission occurs. Dainton defends the view that such cases involve just a single person who has a branching personal time. The person is spatially singly located prior to the fission and spatially bilocated after the fission. Lewis and Dainton endorse analogous accounts of fusion, respectively.

With this in mind, suppose that, at the personal age of 25 years, Carlos is kidnapped and forced to undergo a biological fusion procedure with a man, Karl, who looks as though he might be Carlos's grandfather. The output of the procedure is a man, Charles, who is intermediate in appearance between Carlos and Karl and is psychologically, spatiotemporally, and materially continuous with each of them. Some years later, Charles changes his name to Karl, eventually orders the kidnapping of Carlos, and undergoes the fusion procedure described earlier.

Neither Lewis nor Dainton discusses such a case, but their theories apply to it. Despite their disagreement about 'ordinary' fission and fusion, their theories entail that the present case involves just a single person who fuses with himself. ${ }^{42}$ There is an initial, 25 -year-long stretch of Carlos's personal time, which merges at a certain moment with another stretch of his personal time that is circular and (say) 70 years in length. There is no final moment or final year of his personal time, and he is alive throughout. His personal time has the structure of a circle, ordered by clockwise arrows, with a single on-ramp, which is finitely long. Suppose that this 'Lewis-Dainton interpretation' of the case is correct. Is Carlos immortal? According to my account, he is. At any moment of his personal time, he has at least 70 personal years of life to look forward to.

Third, return to case 6, involving Mary, whose 95 years of personal time are stretched out to fill infinitely many years of external time. Since Mary is alive at each moment of her personal time, and since there is no last such moment, I said that she doesn't die at any moment. And since there is no instant of external time that serves as the relevant sort of 'limit' for her - her external lifespan has an infinite future with no final instant or final year - I said that she doesn't die at any instant. On the basis of these same facts, Sorensen claims that (his version of) Mary is immortal. But he thinks that she is 'cheated' out of something that one would ordinarily expect to come along with immortality, namely, an always infinite personal future.

\footnotetext{
${ }^{42}$ According to Lewis, "a continuant is a person if and only if it is a maximal R-interrelated aggregate of personstages" (1983: 60). There are only two continuants in the case that have any prima facie claim to satisfy this condition. One of them has a spatiotemporal shape that is analogous to a ' $\rho$ ', the other to the same shape minus the stem, roughly, an ' $o$ '. But since the latter is a mere proper part of the former, the latter is not a maximal $\mathrm{R}$ interrelated aggregate, hence not a person, for Lewis.
} 
I say that Mary is not immortal. Her personal time is not circular, and it is only finitely long. For any positive real number, there is a moment in Mary's personal time when she has fewer than that many minutes of her personal time left to live. True, Mary never dies and she has an external lifespan with an infinite future, but she is not immortal. I have argued on independent grounds (cases $1-4$ ) that facts about personal time are relevant to questions about when a person dies. If I am right, then it is to be expected that facts about personal time are also relevant to whether a given person is immortal.

Thus, with regard to Sorensen's two main cases, he and I have opposite verdicts. He takes Mary but not John to be immortal. I have argued that it is the other way around. ${ }^{43}$

\section{References}

Baker, Lynne R. 2000. Persons and Bodies: A Constitution View (Cambridge: Cambridge University Press).

Barrow, John D. 2005. The Infinite Book: A Short Guide to the Boundless, Timeless, and Endless (New York: Pantheon Books).

Bergström, Lars. 2013. 'Death and Eternal Recurrence,' in Ben Bradley, Fred Feldman, and Jens Johansson, eds., The Oxford Handbook of Philosophy of Death (Oxford University Press: 2013), pp. 167-185.

Bernstein, S. 2015. 'Nowhere Man: Time Travel and Spatial Location', Midwest Studies in Philosophy 39: 158-168.

Bricker, Phillip. 1985. 'On Living Forever'. Unpublished manuscript. Available online at: http://blogs.umass.edu/bricker/files/2013/08/On-Living-Forever.pdf

Dainton, Barry. 2008. The Phenomenal Self. Oxford: Oxford University Press.

Demarest, H. 2015. 'Fission May Kill You (But Not for the Reasons You Thought)', Philosophy and Phenomenological Research (Early Online: 10.1111/phpr.12192).

Feldman, Fred. 1992. Confrontations with the Reaper: A Philosophical Study of the Nature and Value of Death (Oxford: Oxford University Press).

Gilmore, Cody. 2007a. "Defining 'Dead' in Terms of 'Lives' and 'Dies,'” Philosophia 35: 219-231.

Gilmore, Cody. 2007b. "Time Travel, Coinciding Objects, and Persistence," in Dean Zimmerman, ed., Oxford Studies in Metaphysics, vol. 3 (2007): 177-198.

Gilmore, Cody. 2010. "Coinciding Objects and Duration Properties: Reply to Eagle," in Dean Zimmerman, ed., Oxford Studies in Metaphysics, vol. 5, pp. 95-111.

Gilmore, Cody. 2013. "When Do Things Die?," in Ben Bradley, Fred Feldman, and Jens Johansson, eds., The Oxford Handbook of Philosophy of Death (Oxford University Press: 2013), pp. 5-59.

Horwich, Paul. 1987. Asymmetries in Time (Cambridge, MA: MIT Press).

Huntington, Edward V. 1924, 'Sets of Completely Independent Postulates for Cyclic Order,' Proceedings of the National Academy of Sciences of the United States of America 10: 7478

\footnotetext{
${ }^{43}$ I am grateful to the Immortality Project, directed by John Martin Fischer and funded by the John Templeton Foundation, for supporting a year of research leave during which a draft of this paper was written. Thanks also to an audience at the Immortality Project Capstone Conference at UC Riverside in 2015, and especially to Ben Bradley, Philip Swenson, Eric Yang, and two referees for this journal for their very helpful comments.
} 
Jenkins, Scott. 2012. 'Time and Personal Identity in Nietzsche's Theory of Eternal Recurrence,' Philosophy Compass 7/3: 208-217.

Lewis, David. 1976. 'The Paradoxes of Time Travel,' American Philosophical Quarterly 13: 145152.

Lewis, David. 1983. "Survival and Identity," in David Lewis, Philosophical Papers, Volume I (Oxford: Oxford University Press), pp. 55-72.

Lewis, David. 1986. On the Plurality of Worlds (Oxford: Blackwell).

Merricks, Trenton. 2009. 'The Resurrection of the Body,' in Thomas P. Flint and Michael Rea, eds., The Oxford Handbook of Philosophical Theology (Oxford: Oxford University Press), pp. 476-490.

Milne, Edward A. 1952. Modern Cosmology and the Christian Idea of God (Oxford: Clarendon Press).

Moore, A. W. 1990. The Infinite (London: Routledge).

Newton-Smith, W. H. 1980. The Structure of Time (London: Routledge \& Kegan Paul).

Novák, Vítězslav. 1984. 'Cuts in cyclically ordered sets', Czechoslovak Mathematical Journal 34: 322-333.

Nowacki, M. 2006. 'Death stings back: A reply to Sorensen', Analysis (2006) 66 (1): 82-92.

Richmond, Alasdair M. 2013. 'Hilbert's Inferno: Time Travel for the Damned,' Ratio 26: 233-249. Rosen, G. MS. 'Real Definition' (draft of February 2015).

Smith, Nicholas J. J. 2013. 'Time Travel', in The Stanford Encyclopedia of Philosophy (Winter 2013 Edition), Edward N. Zalta (ed.), URL = $<$ http://plato.stanford.edu/archives/win2013/entries/time-travel/>.

Smith, Quentin. 1989. 'A New Typology of Temporal and Atemporal Permanence', Noûs 23: 307-330.

Sorabji, Richard. 2006. Self: Ancient and Modern Insights about Individuality, Life, and Death (Chicago: University of Chicago Press).

Sorensen, Roy. 2005. 'The Cheated God: Death and Personal Time.' Analysis 65.2: 119-125.

Thomson, Judith Jarvis. 2008. 'People and Their Bodies', in J. Hawthorne, T. Sider, and D. Zimmerman, eds., Contemporary Debates in Metaphysics (London: Blackwell), pp. 155176.

Tipler, Frank. 1994. The Physics of Immortality: Modern Cosmology, God, and the Resurrection of the Dead (New York: Doubleday).

Donald C. Williams. 1967. 'The Myth of Passage,' in Richard M. Gale, ed., The Philosophy of Time: A Collection of Essays (Garden City, New York: Anchor Books), pp. 98-116.

van Fraassen, Bas C. 1970. An Introduction to the Philosophy of Time and Space (New York: Random House). 